\title{
Influência da adição de resíduo de gesso no calor de hidratação da argamassa de revestimento interno
}

The influence of the addition of gypsum waste on the heat of hydration of mortar for interior plastering

\section{Luiz Fernando Bernhoeft \\ Alexandre Duarte Gusmão \\ Yêda Vieira Póvoas Tavares}

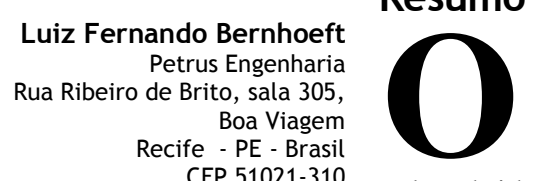

Resumo valor obtido por meio de ensaio de consistência normal, e executados ensaios comparativos entre o gesso natural e o gesso aditivado com 5\% e $10 \%$ de resíduo.

Para as adições de $5 \%$ e $10 \%$ de resíduo, os resultados mostraram a diminuição dos tempos de pega (inicial e final) diretamente correlacionado ao incremento da adição, claramente observados nas curvas de calor de hidratação, porém sem redução proporcional no tempo útil das argamassas, indicando uma alternativa para a diminuição do tempo improdutivo na mistura da pasta de gesso.

Palavras-chave: Reciclagem. Gesso. Resíduo. Revestimento.

\section{Abstract}

The aim of this study was to analyze the influence of adding recycled gypsum waste as an aggregate on the heat of hydration of gypsum mortar for use in internal plastering. The water/plaster ratio was set at 0.66, a value obtained through a natural consistency test, and comparative tests were carried out on natural gypsum and gypsum with 5\% to $10 \%$ addition of waste. The results for plaster with 5 and $10 \%$ added waste showed a decrease in the setting time (initial and final) directly correlated with the increase in the addition of waste. That was clearly seen in the hydration heat curves, but without a proportional reduction in the useful time of the mortars, indicating an alternative to decrease the share of unproductive time in the mixing of gypsum mortar.

Keywords: Recycling. Gypsum. Waste. Plastering. 


\section{Introdução}

A indústria da construção civil é responsável por uma elevada extração de recursos naturais do planeta (GUSMÃO, 2008), sendo a busca por aglomerantes, agregados e demais materiais o motivo da extração, o que, posteriormente, se torna um grande gerador de resíduos.

Entre os materiais que têm sua utilização em largo crescimento na construção civil, destaca-se o gesso. Este pode ser considerado o aglomerante mais antigo que se conhece. Amostras desse material foram abundantemente encontradas em obras do Antigo Egito, Pirâmide de Keops (2800 a.C.), além de ser encontrado em ruínas do nono milênio a.C. na Turquia e em ruínas do sexto milênio a.C. em Jericó (BALTAR; BASTOS; LUZ, 2005). As técnicas de utilização desse material, como a calcinação, e suas propriedades hidráulicas eram conhecidas por esses povos antigos, possibilitando que seu emprego fosse variado, desde a confecção de objetos decorativos, como estátuas, até a construção civil, em processos tão conhecidos pela engenharia atual, como revestimentos de paredes na forma de argamassas e pastas (ANTUNES, 1999).

Nos dias atuais, a utilização desse mineral vem crescendo de forma relevante, o que é verificado pelo volume consumido, especialmente no contexto da construção civil.

A construção civil, que tradicionalmente é um grande agente gerador de resíduo, seja por falta de visão ou de consciência dos aspectos ambientais, seja por falta de tecnologia, e ainda por deficiência na aplicação da tecnologia, requer um cuidado especial devido ao aumento do consumo de gesso. É importante destacar que a Resolução n 307 do Conselho Nacional do Meio Ambiente (CONAMA), que entrou em vigor em 2003, classifica o gesso como um resíduo pertencente à classe "C", requerendo, portanto, uma destinação especial.

\section{Revestimento em gesso}

A extração da gipsita apresenta basicamente duas destinações: em sua forma natural, a gipsita é muito utilizada na agricultura e na indústria cimenteira; na forma calcinada (gesso), é amplamente utilizada na construção civil e nas áreas médica e odontológica, como material ortopédico e dental, entre outros de menor relevância (BALTAR; BASTOS; LUZ, 2005). Sua destinação na fabricação do cimento apresenta uma relevância óbvia na construção civil, por se tratar de seu aglomerante principal. Em sua forma calcinada, na construção civil, o gesso é utilizado basicamente para fundição e para revestimento.

$\mathrm{O}$ material destinado à fundição é usado na fabricação de pré-moldados, como peças para decoração, placas para forro, blocos de gesso, chapas de gesso acartonado, entre outros. O gesso para revestimento é empregado para revestir paredes e tetos de ambientes internos e secos, e essa utilização tem quebrado paradigmas e temores dentro do ramo da construção, ganhando cada vez mais espaço e importância nos canteiros de obras.

O gesso para revestimento tem sido visto pelas construtoras como um material alternativo que não deixa a desejar, por sua qualidade e baixo custo, uma vez que o revestimento em pasta de gesso pode substituir a camada de chapisco, a argamassa (emboço/massa única) e, na etapa de preparação para pintura (nos casos de utilização desse sistema), a massa corrida.

Como afirma Pires Sobrinho (2009), as vantagens do revestimento em gesso também estão ligadas à mistura fácil, utilizando-se apenas a água e o próprio gesso, dispensando o uso de agregados, fato importante, uma vez que a construção civil é considerada uma vilã para o esgotamento desses recursos naturais no planeta (GUSMÃO, 2008).

É sabido que o revestimento de gesso bem utilizado pode promover superfícies mais planas e regulares, possibilitando menores espessuras, pela não necessidade de utilização de agregado, desejáveis e necessárias às edificações racionalizadas. Além disso, o gesso proporciona menor custo e maior produtividade no serviço, aumentando a competitividade de empresas que dominam essa técnica (ANTUNES, 1999). Seu endurecimento rápido propicia a diminuição do tempo para aplicação do acabamento final, em relação à argamassa produzida à base cimentícia. A soma desses fatores, associada a ganhos em materiais, cronograma e projeto, em geral, traz como consequência retorno financeiro, fazendo da utilização de revestimentos em pasta de gesso uma possibilidade de estratégia, em um mercado cada vez mais concorrido.

Além disso, do ponto de vista físico/mecânico, o revestimento em pasta de gesso apresenta excelente capacidade de aderência em diversos tipos de substratos, desde os mais tradicionais em vedações na construção civil, como alvenarias em blocos cerâmicos ou concreto, até em madeiras e cerâmica (PIRES SOBRINHO, 2009). 


\section{Gesso: vilão de RCD}

Como propõe Gasi (2002), a hierarquia adequada no gerenciamento de resíduo é:

(a) não gerar (eliminar o resíduo);

(b) minimizar a geração;

(c) reciclar no processo;

(d) reciclar fora do processo;

(e) fazer tratamento; e

(f) controlar a disposição final.

Porém, certamente nem toda tecnologia e conhecimento na área de gestão à disposição do mercado tem sido utilizada para alcançar metas mais coerentes com a evolução. A deficiência/ausência da gestão do resíduo da construção muitas vezes não torna possível obter sucesso nos itens "a" e "b" dessa hierarquia. Assim, esta pesquisa apresenta-se como uma alternativa relevante para reciclar resíduo de pasta de gesso no próprio processo (canteiro), o que foi a grande motivação do Sindusgesso/PE, no incentivo à adoção de procedimentos de reciclagem junto às empresas aplicadoras.

Quando se analisa a energia empregada no processo de fabricação, a aplicação do revestimento de pasta de gesso apresenta inquestionável vantagem ambiental, quando comparada a argamassas de base cimentícia. Isso porque, segundo Nolhier (1986), para calcinação da gipsita utilizam-se temperaturas entre $180{ }^{\circ} \mathrm{C}$ e $200{ }^{\circ} \mathrm{C}-\mathrm{o}$ cimento Portland é calcinado entre $1.400{ }^{\circ} \mathrm{C}$ e $1.450{ }^{\circ} \mathrm{C}$ (MEHTA; MONTEIRO, 1994).

O mesmo fator que faz do produto um diferencial positivo de rapidez na aplicação torna-se um grande desafio quando observado do prisma ambiental. A grande geração de resíduo devido especialmente a seu rápido endurecimento, associada à falta de consciência e de tecnologia aplicada ao processo de aplicação de pasta de gesso em revestimentos, resulta em perdas estimadas em torno de $30 \%$ dela (JOHN; CINCOTTO, 2003).

Um levantamento elaborado em três obras na cidade do Recife remeteu ao incrível percentual de $47 \%$, fazendo da aplicação do gesso em pasta o maior gerador proporcional de resíduo nas obras, ou seja, apresenta o maior percentual de perda relativo ao material empregado no serviço (GUSMÃO, 2008).

O problema dessa geração de resíduo mostra um agravante, além da óbvia problemática econômica, que é o impacto ecológico. Afinal, segundo a
Resolução $n^{\circ} 307$ do CONAMA, esse resíduo pertence à classificação $C$, uma vez que é um resíduo para o qual não foram desenvolvidas tecnologias ou aplicações economicamente viáveis que permitam sua reciclagem/recuperação. Ou seja, esse resíduo requer destinações especiais, o que difere da grande parte dos resíduos de construção, que são, em sua maioria, inertes e de classe A.

É possível imaginar a dimensão da problemática observando a impossibilidade de utilização das destinações mais comuns para os resíduos da construção e demolição não apenas do resíduo de gesso mas também do resíduo contaminado com gesso.

Essas impossibilidades são registradas e justificadas pelos motivos a seguir.

\section{Como agregados para produtos cimentícios}

A presença do gesso compromete sua utilização, uma vez que a reação entre os aluminatos do cimento e o sulfato do gesso, associada à presença de umidade, gera a etringita, composto que ocupa volume superior ao do reagente original, criando tensões (fruto dessas reações químicas) expansivas, que levam à desagregação das peças de concreto e de revestimentos com base cimentícia (JOHN; CINCOTTO, 2003).

Admite-se como razoável a limitação do teor de sulfatos nos agregados a um valor-limite de $1 \%$ (JOHN; CINCOTTO, 2003). Porém, uma das características dos resíduos de construção é sua heterogeneidade, de modo que cada volume/caçamba apresenta diferenças muitas vezes relevantes entre si.

$\mathrm{Na}$ ausência de controle/gestão dos resíduos gerados na etapa de acabamento, especialmente obras com revestimentos de gesso, esses volumes tendem a conter teores de sulfato muito mais elevados do que o admissível, ou seja, a omissão da gestão de resíduo da construção implementada no canteiro de obra permite que uma pequena parte do resíduo de gesso possa comprometer a maior parte ou a totalidade dos resíduos que possuiriam uma destinação mais ampla e com menores custos. Diante desse quadro, pode-se afirmar que o crescimento (inevitável) do teor de gesso em resíduos deverá exigir controles maiores.

\section{Como agregados para pavimentação e aterro}

Sendo o gesso solúvel em água, a existência dele em aterro ou base de pavimentação irá, 
inevitavelmente, resultar em vazios oriundos de sua lixiviação, podendo, assim, comprometer no médio e longo prazos o serviço executado.

Pode-se citar, ainda, possível alteração de composição do $\mathrm{pH}$ da água do solo, contaminando lençol freático, o que pode resultar em danos ao meio ambiente (JOHN; CINCOTTO, 2003).

Ainda descrevendo sobre a dificuldade de destinação do resíduo de gesso, além de seus desafios de reutilização, esse material, diferentemente dos resíduos classe $\mathrm{A}$, não pode ser depositado em aterros sanitários, pois o gesso em contato com umidade/água, em condições anaeróbicas, com baixo pH, e sob ação de bactérias redutoras de sulfatos (condição existente em muitos aterros sanitários e lixões) pode formar um gás com o odor característico de ovo podre, que é o gás sulfídrico, sendo ainda tóxico e inflamável (CALIFORNIA..., 2003).

$\mathrm{Na}$ prática, especialmente quanto aos pequenos geradores, muitas vezes o gesso é depositado de forma e em local inadequados, de maneira clandestina, gerando grande impacto ambiental e econômico (GUSMÃ̃, 2008), como, por exemplo, próximo a vias, rios e terrenos, como se observa na Figura 1.

\section{Hidratação do gesso}

A hidratação resulta da reação química entre o hemidrato e a água, gerando novamente o dihidrato, por meio da reação inversa da formação de gipsita em gesso, liberando calor (Equação 1).

$$
\begin{aligned}
& \mathrm{CaSO}_{4} \cdot 0,5 \mathrm{H}_{2} \mathrm{O} \text { (hemidrato) }+1,5 \mathrm{H}_{2} \mathrm{O} \rightarrow \\
& \mathrm{CaSO}_{4} \cdot 2 \mathrm{H}_{2} \mathrm{O} \text { (dihidrato) + energia }
\end{aligned}
$$

A hidratação do gesso pode ser monitorada por meio da calorimetria. Antunes (1999) apresentou uma curva típica de calor de hidratação de uma pasta de gesso, ilustrada na Figura 2. Nessa curva registra-se a evolução da temperatura (liberação de energia na reação) em função do tempo, observando-se uma clara divisão em três etapas distintas:

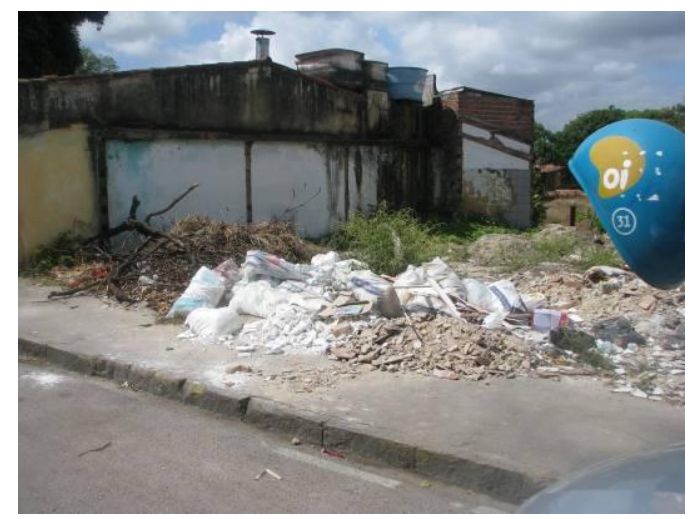

Figura 1 - Destinação inadequada de resíduo de RCD

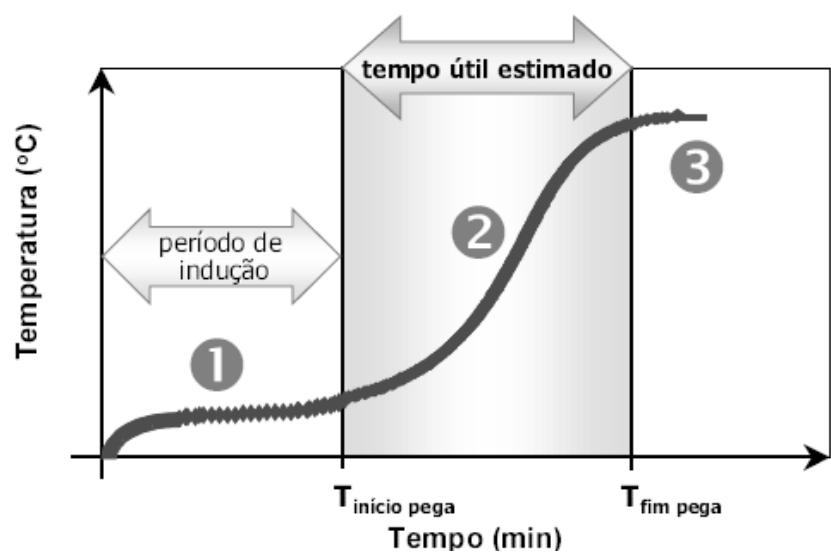

Figura 2 - Curva de hidratação do gesso

Fonte: Antunes (1999). 
(a) etapa 1 - inicial: quando ocorre uma pequena hidratação, seguida pelo período de indução. A indicação de término dessa etapa surge pelo aumento da taxa de elevação da temperatura, ou seja, quando é observada a elevação superior a 0,1 ${ }^{\circ} \mathrm{C} / \mathrm{min}$. Nesse momento, está caracterizado o início de pega;

(b) etapa 2 - evolução rápida da reação de hidratação: esta etapa é caracterizada pela rápida elevação da temperatura e apresenta o momento propício para a aplicação do gesso em pasta para revestimentos; e

(c) etapa 3 - fim de pega: a temperatura atinge seu valor máximo, de modo que foi concluída a hidratação, sendo assim caracterizado o fim de pega. Nesse momento a temperatura medida começa a decrescer.

As informações geradas por essa curva são fundamentais para o estudo da melhor forma e possibilidade de aplicação do gesso, uma vez que se pode observar que, na etapa 1 , o único procedimento produtivo possível é a mistura entre o hemidrato e a água, de modo que boa parte desse período se torna improdutivo.

De todo o tempo utilizado na etapa 1 (Figura 2), apenas uma pequena parte, cerca de $25 \%$, num total aproximado entre $20 \mathrm{~min}$ e $25 \mathrm{~min}$, não é improdutivo, por se tratar do tempo de mistura; o restante é caracterizado apenas pela espera.

Em geral, na etapa 2, tem-se o tempo útil de aplicação da pasta no substrato, indicado pelo momento de elevação da temperatura, quando as reações de hidratação estão em pleno desenvolvimento.

E, por fim, a etapa 3 representa o fim da reação de hidratação e, consequentemente, a impossibilidade de uso da pasta de gesso a partir desse instante.

A exata compreensão dessa curva (Figura 2), assim como de fatores que podem alterar o tempo de cada etapa, pode colaborar com a redução de geração de resíduo, diminuindo o desperdício do material no canteiro de obras.

\section{Tempo útil das pastas de gesso}

Antunes e John (2000) definiram tempo de vida útil da pasta de gesso como "o tempo disponível para aplicação do revestimento em gesso, o intervalo de tempo em que a pasta se encontra dentro da faixa de consistência adequada", ou, ainda, "período reservado ao trabalho produtivo". Esse período apresenta como os dois extremos limitadores as consistências mínima e máxima, ou seja, a consistência útil da pasta de gesso, obtida por meio do ensaio com o aparelho de VICAT modificado, o que corresponde a aproximadamente o início e o fim da pega do gesso, que em valores teóricos, segundo a NBR 13207 (ABNT, 1994a), tem-se tempo maior do que $10 \mathrm{~min}$ e tempo maior do que 45 min respectivamente, gerando um tempo de vida útil estimado em aproximadamente 35 $\min$.

Observa-se na Figura 2 que a etapa 3 registra o fim da possibilidade de uso da pasta de gesso, a chamada "morte do gesso". Sendo assim, o período teórico produtivo refere-se às etapas 1 e 2 . Todavia, é sabido que a etapa 1 tem grande parte de seu tempo dedicada apenas à espera do início das reações, reduzindo, assim, o tempo produtivo real.

Antunes, John e Andrade (1999) mostraram, na Figura 3, os percentuais relacionados às etapas $1 \mathrm{e}$ 2.

A Figura 3 apresenta um período totalmente improdutivo, de aproximadamente $30 \%$. Esse fato tem sido motivador de diversas pesquisas para analisar a influência de adições e aditivos, e de técnicas de aplicação da pasta de gesso, de modo a minimizar o tempo sem produtividade, visando produzir resultados financeiros sem comprometimento técnico e/ou ambiental.

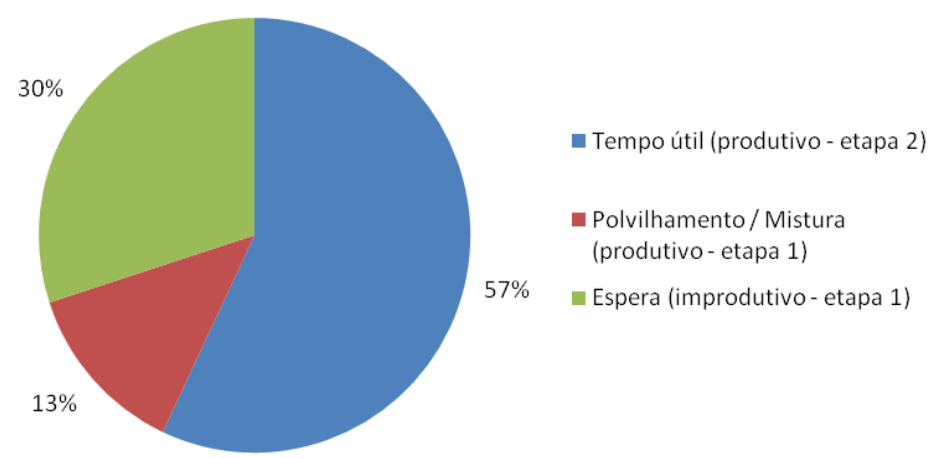

Figura 3 - Divisão percentual proposta por Antunes, John e Andrade (1999) do tempo de utilização da pasta de gesso 


\section{Fatores que influenciam a cinética das reações do gesso}

Diversos fatores influenciam na cinética da reação de hidratação do gesso. Pode-se mencionar com destaque:

(a) a relação água/gesso $(\mathrm{a} / \mathrm{g})$;

(b) a energia de mistura do gesso com a água;

(c) a temperatura da água de amassamento;

(d) a umidade relativa do ar no ambiente de trabalhado;

(e) a presença de impurezas/pontos de nucleação; $\mathrm{e}$

(f) ainda, a presença de aditivos (ANTUNES; JOHN; ANDRADE, 1999).

Dos itens retro citados, atribui-se ao fator a/g a maior responsabilidade na influência das reações de hidratação do gesso. Quanto maior a quantidade de água, maior será o tempo necessário para a formação dos cristais de di-hidrato e para a precipitação (início de pega), ou seja, resulta em um aumento no período de indução (NOLHIER, 1986; ANTUNES; JOHN, 2000). Esse é um aspecto que motiva um procedimento comum de obra: os fatores $\mathrm{a} / \mathrm{g}$ são superiores quando comparados com os resultados obtidos por meio do ensaio de consistência, segundo NBR 12128 (ABNT, 1994). Nos canteiros de obra é comum observar a relação a/g próximo a 0,80 . Todavia, o ensaio de consistência fornece resultados próximos a 0,65 .

Outro fator de grande relevância, cujo conhecimento é vastamente utilizado nas técnicas de aplicação de revestimento em pasta de gesso, é o incremento de energia na mistura. A energia aplicada na mistura aumenta a dispersão do pó na água de amassamento e, por consequência, tem-se a formação de uma quantidade maior de núcleos de cristalização, acelerando o processo de hidratação. O estudo realizado por Blaine (1997) é um exemplo de base científica dos procedimentos adotados comumente em obra, onde os aplicadores de gesso misturam, a princípio, apenas $50 \%$ do volume do conjunto gesso e água no recipiente, de forma a retardar a hidratação da parte em repouso.

Presença de impurezas, que são elementos estranhos à mistura da pasta de gesso, é outro fator que acelera a pega das pastas; agregados, como o próprio di-hidrato ou grãos de areia, atuam como núcleos de cristalização, e, como já apresentado, o aumento desses núcleos favorece a agilidade das reações de hidratação (ANTUNES; JOHN, 2000).
O estudo referente ao maior controle/domínio do tempo de início e de fim de pega, consequentemente do tempo de consistência útil, seja pelo emprego de técnicas de aplicação ou intervenção/adição de materiais que influenciam na cinética da reação, é fundamental na tentativa de minimizar o tempo improdutivo e, assim, maximizar o tempo produtivo da aplicação de pasta de gesso em revestimentos.

\section{Reciclagem do resíduo de gesso em obra}

Seja por consciência ambiental, seja por exigência da legislação, é crescente a preocupação com a gestão de resíduos no canteiro de obra. $\mathrm{Na}$ reciclagem fora do canteiro de obra algumas técnicas são comprovadamente possíveis. Como exemplos citam-se:

(a) correção de solos (agricultura, cultivo de cogumelos);

(b) aditivo para compostagem; forração para animais;

(c) absorvente de óleo;

(d) controle de odores em estábulos; e

(e) secagem de lodo de esgoto (JOHN; CINCOTTO, 2003).

Porém, uma vez que o custo com transportes e eventual recalcinação é elevado, na prática essas ações são pontuais.

Apesar da carência de estudos referentes ao tema da reciclagem/reaproveitamento de pastas de gesso em obra, alguns pesquisadores têm-se dedicado ao tema, podendo se destacar o trabalho de Nita et al. (2004), que analisaram a possibilidade de reciclagem de resíduos de gesso de construção hidratado na produção de gesso de construção, na forma de di-hidrato, finamente moído, como substituição ao gesso hemidrato natural em teores de $0 \%, 1 \%, 2 \%$ e $4 \%$. Para isso, foram utilizados dois fatores água/material sólido $(0,60$ e 0,72$)$. A conclusão do trabalho mostrou o grande potencial para a prática de reutilização de sobras de gesso em revestimentos.

Alencar, Baltar e Miranda (2008) analisaram o desempenho do procedimento utilizado para reciclagem de resíduo gerado em canteiro de obra por uma das empresas da Região Metropolitana do Recife. Executou-se um comparativo de desempenho físico e mecânico de pasta de gesso com adição de resíduo de $10 \%, 15 \%, 20 \%$ e $25 \%$, e um fator água/gesso de 0,75. Observou-se a diminuição do tempo de pega, que, segundo o autor, pode ser administrado pela forma de mistura 
da pasta e adição dos resíduos (parcial). Não foram observadas perdas mecânicas importantes, como aderência e resistência a compressão.

Schmitz (2008) se propôs a avaliar a melhor forma de utilizar o resíduo da pasta de gesso natural no revestimento interno de paredes, de modo que fosse minimizado o comprometimento na qualidade e no desempenho do revestimento. $\mathrm{O}$ pesquisador substituiu $5 \%$ e $10 \%$ de resíduo moído e comparou os resultados com o desempenho do gesso natural. A conclusão do autor se mostrou bastante otimista quanto à viabilidade da reutilização do resíduo gerado no próprio canteiro de obra.

Pires Sobrinho (2009) apresentou metodologia similar àquela apontada por Schmitz (2008) e Alencar, Baltar e Miranda (2008), tendo ensaiado uma série com gesso natural e outras com 5\%, $10 \%, 15 \%, 20 \%$ e $25 \%$ de adição de resíduo. Sua conclusão também foi favorável à aplicação da prática.

Visando aprimorar a tecnologia da reciclagem dos resíduos de gesso em obras, esta pesquisa propõe fornecer informações adicionais referentes à influência dessa adição no tempo útil para aplicação na pasta de gesso, analisando o comportamento da curva do calor de hidratação e comparando o GN (gesso natural) com o G5 (gesso com adição de 5\% de resíduo) e com o G10 (gesso com adição de $10 \%$ de resíduo).

\section{Metodologia e ensaios}

\section{Consistência Normal}

Para a determinação da consistência normal da pasta de gesso adotou-se o procedimento recomendado pela da NBR 12128 (ABNT, 1994b), utilizando-se o aparelho de Vicat Modificado (Figuras 4 e 5). A relação água/gesso utilizada em todos os ensaios foi de 0,66 .

Para a obtenção da relação água/gesso foi utilizada a mistura com gesso natural $(\mathrm{GN})$, para se obter um resultado de consistência igual a $(30 \pm 2) \mathrm{mm}$, como indica a NBR 12128 (ABNT, 1994b).

Para esse objetivo utilizaram-se $150 \mathrm{~g}$ de água com adição de retardador ( $10 \mathrm{~g}$ de solução de citrato de sódio dissolvido em concentração de $2 \%$ ). Foram executadas tentativas registradas na planilha da Tabela 1, onde o hemidrato era polvilhado durante 1 min na água, passando por um descanso de 2 min, e, por fim, misturado por $1 \mathrm{~min}$ para posterior colocação no molde do aparelho de Vicat Modificado, para a obtenção da medida da consistência.

Como se pode observar na Tabela 2 , a relação água/gesso para penetração ideal foi obtida com 227 g de gesso, ou seja, relação água/gesso de $150 / 227=0,66$.

Figura 4 - Esquema do aparelho de Vicat Modificado

Fonte: Antunes (1999).
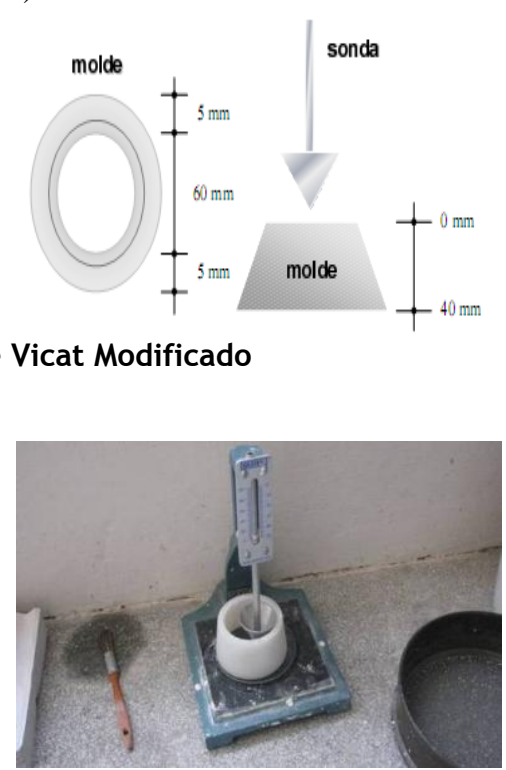

Figura 5 - Aparelho de Vicat Modificado utilizado no LACC - POLI/UPE

Tabela 1 - Tentativas para a obtenção da consistência $(30 \pm 2) \mathrm{mm}$

\begin{tabular}{l|c|c|c|c}
\hline & Teste 1 & Teste 2 & Teste 3 & Teste 4 \\
\hline Massa de água $(\mathbf{g})$ & 150 & 150 & 150 & 150 \\
\hline Massa de gesso $(\mathbf{g})$ & 200 & 214 & 220 & 22 \\
\hline Penetração $(\mathbf{m m})$ & 37 & 34 & 33 & 30 \\
\hline
\end{tabular}


Tabela 2 - Relação água/elementos sólidos do programa experimental

\begin{tabular}{l|c|c|c}
\hline \multicolumn{1}{c|}{ Relação } & GN & G5 & G10 \\
\hline Relação água/gesso & 0,66 & 0,66 & 0,66 \\
\hline Relação água/elementos sólidos & 0,66 & 0,63 & 0,60 \\
\hline
\end{tabular}

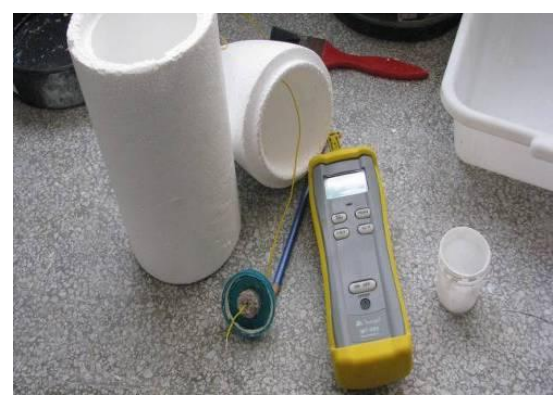

Figura 6 - Calorímetro pseudoadiabático, montado no LACC - POLI/UPE

Tendo em vista que as amostras utilizadas incluíam adições de $5 \%$ e $10 \%$ de resíduo beneficiado, é possível observar na Tabela 2 os valores das relações água/elementos sólidos, que foram utilizados em todo o programa experimental.

\section{Calor de hidratação}

Este ensaio teve como objetivo principal a obtenção das curvas de calor de hidratação. Tais curvas possibilitam efetuar a análise do comportamento da pasta e das argamassas à base de gesso, observando com clareza as delimitações das etapas 1 (indução), 2 (consistência útil) e 3 (fim do período de utilização), como ilustra Antunes (1999) na Figura 2.

A curva ainda indica o tempo de início e de fim de pega por meio da análise das curvas de calor de hidratação em função do tempo, gerado pela variação de temperatura durante as reações de hidratação do gesso (que libera energia). O parâmetro adotado para determinar o início de pega foi a observação de quando o gradiente térmico ultrapassasse $0,1^{\circ} \mathrm{C} / \mathrm{min}$, e o fim de pega foi o instante em que a temperatura máxima foi atingida, evidenciado pela interrupção da elevação de temperatura.

Neste ensaio foi utilizado um calorímetro pseudoadiabático proposto por Murat e Jeandot (1973) e um cronômetro (Figura 6).

$\mathrm{O}$ procedimento de mistura foi o mesmo utilizado no ensaio de tempo de pega. Após a mistura, a amostra foi colocada dentro de um recipiente plástico, conectado ao termômetro. Posteriormente, o recipiente foi colocado em garrafa térmica visando à não interferência do ambiente externo.
Neste ensaio a temperatura foi medida a cada minuto, passando por sua elevação brusca de temperatura (ápice das reações), até o momento em que o aumento da temperatura foi interrompido, sendo alcançada a temperatura máxima.

\section{Resultados}

A variação de temperatura em função do tempo de GN, como de G5 e de G10, é expressa na Figura 7, resultando em uma curva típica do calor de hidratação, sendo possível identificar suas três etapas.

Considerando o tempo T1 como sendo o momento em que o gradiente térmico ultrapassava 0,1 ${ }^{\circ} \mathrm{C} / \mathrm{min}$ (considerado o tempo de início de pega), e o tempo T2, o momento em que a temperatura atingia seu máximo (considerado o tempo de fim de pega), gerou-se o comparativo entre a pasta GN e as argamassas G5 e G10 (Figura 8).

Considera-se possível o tempo útil para aplicação das argamassas de gesso, a diferença entre T2 e T1. No caso dos ensaios apresentados, é possível registrar que, não obstante a relevante diminuição de T1 - 9 min para G5 e 10 min para G10 -, conforme a Figura 11, observa-se a pequena diminuição do tempo útil, especialmente para G5, de $4 \%$, e G10, de $30 \%$, quando comparado com GN (Figura 9).

Esses números mostram uma potencial possibilidade da adição do resíduo, especialmente em teores de 5\%, para ser utilizado na minimização do tempo improdutivo da aplicação do gesso, diminuindo T1 e, consequentemente, o tempo de espera das reações de hidratação, sem, contudo, comprometer o tempo útil, ou seja, o intervalo $\mathrm{T} 2-\mathrm{T} 1$. 


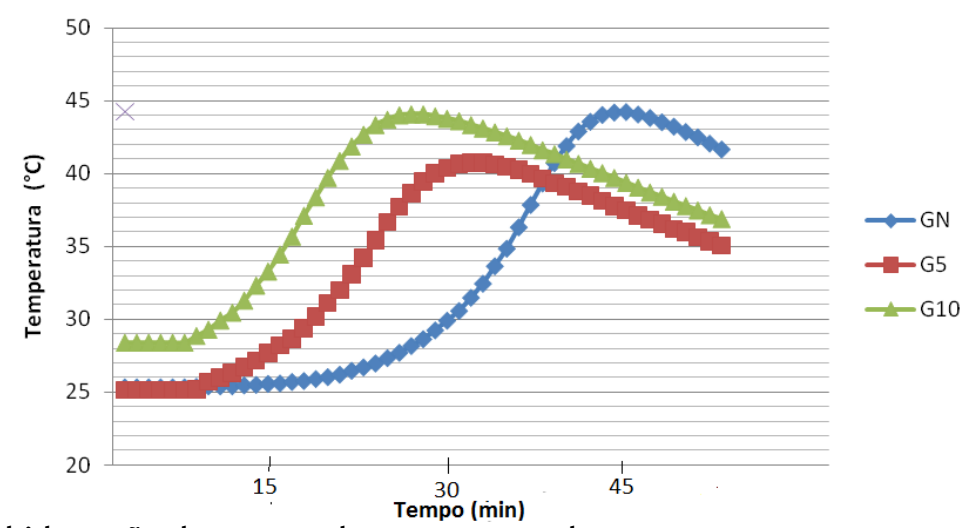

Figura 7 - Calor de hidratação da pasta e das argamassas de gesso

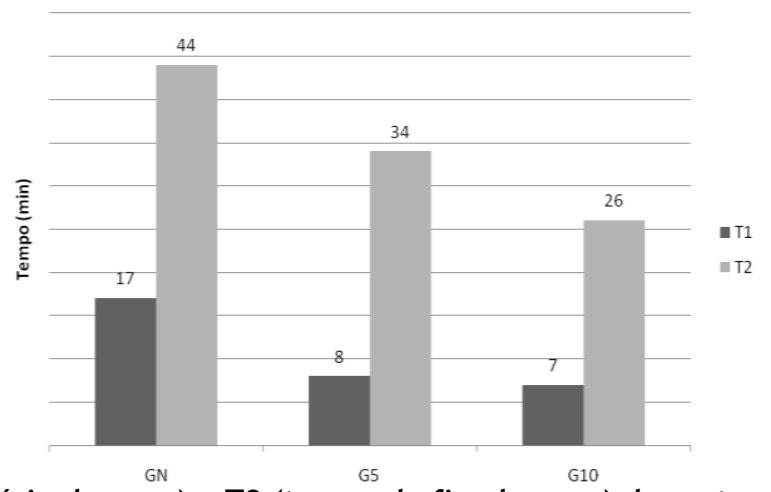

Figura 8 - T1 (tempo de início de pega) e T2 (tempo de fim de pega) da pasta normal, com a adição de resíduos

Figura 9 - Tempo útil das argamassas

\section{Considerações finais}

A tecnologia de aplicação do revestimento de gesso na construção civil não tem acompanhado o grande avanço tecnológico do setor nos últimos anos, sendo evidente o elevado desperdício e geração de resíduo.

Os procedimentos de reaproveitamento de resíduos no próprio canteiro, adicionando sobras moídas à pasta de gesso, têm mostrado indicativo de viabilidade.
A adição de resíduo à pasta de gesso diminui os tempos de início de pega da argamassa de gesso (53\% para adição de $5 \%$, e $59 \%$ para adição de $10 \%)$, assim como do tempo de fim de pega $(23 \%$ para adição de $5 \%$, e $41 \%$ para adição de $10 \%$ ), fato que pode indicar a possibilidade da diminuição do tempo improdutivo de espera. Maior atenção deve ser dada para que não ocorra a diminuição do tempo da faixa de consistência útil, pois, afinal, o rápido endurecimento das argamassas seria acelerado, tornando-se um agravante à problemática da geração de resíduo do revestimento de gesso. 
Ensaios de calor de hidratação comparativos entre pasta de gesso natural e argamassa com adição de $5 \%$ do resíduo vislumbram a possibilidade de manter-se o tempo de consistência útil, especialmente no desenvolvimento de fatores e métodos controlados correspondentes ao processo de aplicação.

\section{Referências}

ALENCAR, C.; BALTAR, L.; MIRANDA, L. F. R. Avaliação da Reciclagem de Resíduos de Gesso em Canteiros-de-Obras do Recife. In: CONGRESSO INTERNACIONAL DE TECNOLOGIA APLICADA PARA ARQUITETURA E ENGENHARIA SUSTENTÁVEIS, 2008, Receife. Anais... Recife, 2008.

ANTUNES, R. P. N.; JOHN, V. M.; ANDRADE, A. C. Produtividade dos Revestimentos de Gesso: influência das propriedades do material. In. SIMPÓSIO BRASILEIRO DE GESTÃO DA QUALIDADE E ORGANIZAÇÃO DO TRABALHO, 1., 1999, Recife. Anais... Recife: ANTAC, 1999.

ANTUNES, R. P. N. Estudo da Influência da Cal Hidratada nas Pastas de Gesso. São Paulo, 1999. Dissertação (Mestrado em Engenharia Civil) - Escola Politécnica, Universidade de São Paulo, São Paulo, 1999

ANTUNES, R. P. N.; JOHN, V. M. O Conceito de Tempo Útil das Pastas de Gesso. São Paulo: Escola Politécnica da Universidade de São Paulo, 2000. Boletim técnico.

ASSOCIAÇÃO BRASILEIRA DE NORMAS TÉCNICAS. NBR 13207: gesso para construção civil: especificação. Rio de Janeiro, 1994a.

ASSOCIAÇÃO BRASILEIRA DE NORMAS TÉCNICAS. NBR 12128: gesso para construção civil: determinação das características físicas da pasta. Rio de Janeiro, 1994b.

BALTAR, C. A. M.; BASTOS, F. F.; LUZ, A. B. Rochas e Minerais Industriais. Ministério da Ciência e Tecnologia, Centro De Tecnologia Mineral, 2005. cap. 21.

BLAINE, S. Accelerating the Hydration of Calcium Sulfate Hemihydrates Via High Energy Mixing. Materials and Structures, v. 30, p. 362365, jul. 1997.
CALIFORNIA Integrated Waste Management Board. Drywall Recycling. Disponível em: <http://www.ciwmb.ca.gov/ConDemo/factsheets/ Drywall.htm\#Economics $>$. Acesso em: 01 set. 2003.

CONSELHO Nacional do Meio Ambiente. RESOLUÇÃO CONAMA n ${ }^{\circ} 307$, de 5 de julho de 2002. Publicada no DOU no 136, de 17 de julho de 2002, Seção 1, páginas 95-96.

GASI, T. Mesa Redonda Paulista de Produção Mais Limpa. In: CONFERENCIA PAULISTA DE PRODUÇÃO MAIS LIMPA, 4., 2002. Anais... São Paulo, 2002.

GUSMÃO, A. D. Manual de Gestão dos Resíduos da Construção Civil. Camaragibe, PE: CSS, 2008.

JOHN, V. M.; CINCOTTO, M. A. Reciclar para Construir: alternativas de Gestão do Resíduo de Gesso. São Paulo: Escola Politécnica da Universidade de São Paulo, 2003.

MEHTA, P. K.; MONTEIRO, P. J. M. Concreto: estrutura, propriedades e materiais. São Paulo: PINI, 1994.

MURAT, M.; JEANDOT, G. Méthodes de Mésures et Interprétation des Effets Thermiques Associés à l'Hydratation des Sulfates de Calcium et des Plâtres Industriels. Rêvue de Matériaux de Construction, v. 680, p. 14-23, 1973.

NITA, C. et al. Estudo da Reciclagem do Gesso de Construção. In: ENCONTRO NACIONAL DE TECNOLOGIA DO AMBIENTE CONSTRUÍDO, 2004; CONFERÊNCIA LATINO-AMERICANA DE CONSTRUÇÃO SUSTENTÁVEL, 2004. Anais... São Paulo: Antac, 2004.

NOLHIER, M. Construire em Plâtre. Paris: L'Harmattan, 1986.

PIRES SOBRINHO, C. W. Influência da Adição de Resíduos de Gesso nas Propriedades Mecânicas das Pastas para Revestimento. In: ENCONTRO NACIONAL SOBRE APROVEITAMENTO DE RESÍDUOS NA CONSTRUÇÃO CIVIL; SEMINÁRIO SOBRE RESÍDUOS SÓLIDOS DA CONSTRUÇÃO CIVIL, 1., 2009. Anais... Feira de Santana, 2009.

SCHMITZ, I. B. T. A. Estudo da Reciclagem da Pasta de Gesso para Construção Civil. Relatório de Pesquisa. Recife: Universidade de Pernambuco, 2008. 


\section{Revista Ambiente Construído}

Associação Nacional de Tecnologia do Ambiente Construído

Av. Osvaldo Aranha, $99-3^{\circ}$ andar, Centro

Porto Alegre - RS - Brasil

$$
\text { CEP 90035-190 }
$$

Telefone: +55 (51) 3308-4084

Fax: +55 (51) 3308-4054

www.seer.ufrgs.br/ambienteconstruido

E-mail: ambienteconstruido@ufrgs.br 